\title{
Memórias, identidades e silêncios: a História Local em sala de aula, trabalhada com diferentes gerações
}

\author{
Memories, identities, and silences: teaching the \\ Local History from diferent generations perspectives
}

Mario Sérgio Ignácio Brum*

\section{RESUmo}

$\mathrm{O}$ artigo trata da experiência realizada com alunos de duas escolas em conjugar ensino de História e pesquisa sobre a História Local da Cidade Alta, conjunto surgido no processo de remoção de favelas executado pelos governos federal e estadual do Rio de Janeiro no auge da Ditadura Militar. As diversas memórias e representações trazidas pelos alunos forneceram preciosas fontes e questões sobre o local, permitindo distinguir a formação de estigmas e identidades locais, ao mesmo tempo em que tratávamos temas como a Ditadura Militar, mais próximos de suas experiências. Por fim, as memórias dos alunos, mediadas pelo professor com auxílio de outras fontes, permitiram aos alunos aprender procedimentos de pesquisa histórica, de modo que eles se perceberam como sujeitos da História enquanto a pensavam cientificamente.

Palavras-chave: ensino de História; História Local; estigma e identidades.

\begin{abstract}
The paper discusses a teaching experience conducted with students from two different schools to combine History teaching and Local History. The subject of this experience was the History of Cidade Alta, a housing community that arouse through a government policy to contain slums growth at the Dictatorship period. From the study conducted with narratives of the community through time, it was possible to obtain valuable historical testimonies and memoirs about the site. Moreover, it was possible to perceive how the community stigmas and a local identity emerged, while teaching the Military Dictatorship History closer to their lives experiences. Ultimately, from the study of the students and members of the community memoirs, it was possible to see the learning process of the students conducted with historical research and how they started to perceive themselves as subjects of History, while learning it. Keywords: History teaching; Local History; stigma and identities.
\end{abstract}

\footnotetext{
* Faculdade de Educação, Programa de Pós-Graduação em Educação, Cultura e Comunicação em Periferias Urbanas, Universidade do Estado do Rio de Janeiro (Uerj) - Campus da Baixada Fluminense.mariobrum@yahoo.com.br
} 
Este artigo trata de pesquisa sobre a História, as memórias, os estigmas e as identidades locais de diferentes gerações de moradores da Cidade Alta, localidade na Zona Norte do Rio de Janeiro, cujo núcleo é o conjunto habitacional homônimo que surgiu no fim da década de 1960 para abrigar removidos de favelas, principalmente da Zona Sul do Rio de Janeiro. ${ }^{1}$

A pesquisa originou-se em sala de aula (e nela ocorreu em grande parte) na disciplina História, ministrada por mim inicialmente num colégio de ensino médio desde 2006, e a partir de 2009 também em mais uma escola, com o segundo segmento do ensino fundamental, alcançando no total mais de 2 mil alunos em várias séries, turmas e gerações ao longo dos 5 anos em que a História Local foi o tema trabalhado. Mais do que realizar uma pesquisa acadêmica e uma atividade docente, quisemos que os alunos conseguissem pensar historicamente e, principalmente, buscamos dotar a disciplina História de sua dimensão humana.

A partir da pesquisa sobre a História Local, com a coleta de depoimentos, fotos, documentos oficiais e outras fontes, trabalhamos os procedimentos de pesquisa histórica, além de debatermos em sala de aula diversos temas transversais tais como cidadania, democracia, violência, cultura, Direitos Humanos e direito à memória, entre outros. Objetivamos, com essa atividade, tornar as memórias, a "história que se sabe", em objetos de ensino e pesquisa: história refletida e pensada (Monteiro, 2007, p.59).

\section{ENSINo E PESQUisa}

É importante destacar que nosso trabalho conjugou ensino/aprendizagem e pesquisa em diversos âmbitos. O primeiro é que a compreensão do local, na tarefa de docente e pesquisador, baseava-se na visão de seus moradores/alunos e nas múltiplas identidades existentes, as quais me chegavam por intermédio deles. Foi justamente das discussões em sala de aula durante o ano letivo de 2006 que a pesquisa se originou.

A convivência com os alunos e com outros docentes em escolas que tinham como característica a presença de vários moradores ou ex-moradores como professores, fez com que minha posição não fosse de um simples pesquisador externo, nem de morador. Estava mergulhado no objeto de pesquisa. Ouvia as histórias e narrativas sobre o cotidiano local na entrada das escolas, 
na sala de aula, na sala dos professores e em conversas no corredor, o que me permitia construir um quadro rico e complexo do que era a Cidade Alta, com todas as suas partes, estigmas e identidades - um quadro que precisava ser pensado e debatido.

Ambas as unidades escolares funcionavam no mesmo prédio, na rua principal do "complexo" da Cidade Alta. O Colégio Estadual República de Guiné Bissau era o único de ensino médio, e a Escola Municipal Ministro Lafayette de Andrada a única a ter o segundo segmento do ensino fundamental, além de turmas da Educação de Jovens e Adultos (EJA), na Cidade Alta. Vale dizer que os alunos das escolas eram majoritariamente moradores do complexo da Cidade Alta (incluindo aqui os três conjuntos e as "favelas"), havendo uma minoria que morava no entorno imediato, nos bairros de Cordovil, Brás de Pina e Parada de Lucas.

Desse modo, duas gerações da mesma família compartilhavam o mesmo espaço físico escolar. Além disso, ao menos metade das turmas de ambas as escolas eram meus alunos de História.

A compreensão era de que a pesquisa e as aulas relacionadas com a história local necessariamente seriam um saber partilhado entre alunos e professor, ou, mais do que isso, minha tarefa como pesquisador e professor deveria ser, principalmente, a de auscultar os conhecimentos e as visões dos alunos sobre o local, na compreensão de que tínhamos acúmulos distintos sobre o tema a ser trabalhado e interesses diversos sobre ele (Monteiro, 2003, p.10).

Enquanto os meus acúmulos eram de um "recém-chegado" no tema, os alunos viviam aquela realidade cotidianamente, e muitos tinham ainda o saber acumulado pela família. Em outro sentido, meu interesse era traçar um panorama o mais variado possível dos discursos sobre o local. O principal interesse dos alunos, como moradores, seria o de fazer valer a posição que tivessem, fosse ela com categorias acusatórias e/ou de negação dos estigmas.

$\mathrm{Na}$ atividade docente, com base em conversas na sala de aula, pude observar que os alunos apresentavam variados discursos sobre a condição do local como "favela". Chamava atenção nessas falas o fato de que, passados quase 40 anos da inauguração de um conjunto que surgiu como resposta do Estado à favela, pairassem sobre a Cidade Alta diversas descrições que a identificavam como tal. Discursos que a apontavam como local de violência, de desordem urbana, de informalidade e de pobreza. 
No decorrer da pesquisa e da atividade percebemos que a noção de "fazer parte" da Cidade Alta passava pela definição do status do local como "conjunto", "comunidade" ou "favela", bem como pela classificação de si e dos outros moradores como "favelados" ou "não favelados".

Além disso, como os alunos eram de diversas faixas etárias - desde os 11 anos até mais de 60 anos--, percebemos que os mais velhos, alguns da primeira geração, ${ }^{2}$ têm a memória do surgimento da Cidade Alta como um conjunto que serviu para abrigar os removidos, semelhante a outros da cidade do Rio de Janeiro. Lembram-se, também, de todo o processo de remoção de favelas realizado na cidade do Rio de Janeiro nas décadas de 1960 e 1970. Os mais novos, porém, praticamente todos da terceira ou da quarta geração de moradores (esta última em torno de 10 a 12 anos de idade), desconhecem no todo ou em grande parte essa origem.

Esse corte geracional nos intrigava. Aparentemente, quanto mais jovem, menos o morador sabia sobre a origem da Cidade Alta. Suspeitávamos que esse silêncio em relação à memória estava diretamente relacionado ao estigma de favela que o local carrega, compreendendo, como apontou Circe Bittencourt, que "os vestígios do passado se encontram em diferentes lugares, fazem parte da memória social" (Bittencourt, 2004, p.333).

A presença desses estigmas sobre a Cidade Alta no imaginário local e, numa escala maior, na cidade, e esse silêncio entre gerações nos levaram a realizar a pesquisa em que os alunos lidaram com sua História e as memórias não apenas como pesquisados, mas sobretudo na condição de pesquisadores. Tratava-se de transformar o vivido, suas percepções e representações sobre o passado, em conhecimento produzido coletivamente, entre professor e alunos, todos no papel de pesquisadores.

Dessa forma intentamos em nossas aulas "ensinar o aluno como levantar problemas, procurando transformar ... temas e problemáticas em narrativas históricas" (Schmidt; Cainelli, 2004, p.90). Havia uma memória difusa, principalmente entre os mais jovens, em que a origem do conjunto, o passado de favela de seus pais e avós e a remoção eram algo "distante" no tempo e quase desvinculado de suas vidas e realidades, constituído de memórias traumáticas e silêncios, com reflexos diretos na maneira como os moradores da Cidade Alta viam a si próprios. Tratava-se de transformar essa memória numa narrativa em que os alunos compreendessem a história do local em que viviam e, em 
termos mais gerais, da cidade e do país, a história de seus pais, tios e avós e a deles mesmos.

\section{Metodologia dos “Trabalhos”}

A primeira atividade consistiu num debate em sala sobre diversas impressões que os alunos apresentaram durante todo o ano, em conversas informais ou mesmo em analogias às matérias (quando falávamos, por exemplo, do poder dos senhores feudais e os alunos teciam ligações com o chefe do tráfico local), com o devido cuidado, como alerta Monteiro (2005), de não cair em anacronismos ou de confundir mais do que esclarecer.

Um elemento predominava nessas conversas: a condição de "favela" do local. Embora não consensual, o tema era forte entre os alunos. E esse discurso vinha acompanhado de mais dois elementos: falavam da beleza, tranquilidade e ordenação anteriores da Cidade Alta, e concluíam com uma forte acusação aos vizinhos/outros moradores, imputando a eles a responsabilidade pela transformação do local em "uma favela".

Realizamos o primeiro trabalho com turmas de $1^{\circ}$ e $2^{\circ}$ anos. No início, em 2006, o Colégio Estadual República de Guiné Bissau tinha ao todo 12 turmas, 4 em cada série, e o critério de alocação dos alunos geralmente se dava pela idade - a turma 1 era composta por alunos mais novos, e a turma 4 pelos mais velhos (embora alterações durante o ano fossem comuns). O trabalho, que valia a nota do $3^{\circ}$ bimestre na disciplina de História, consistia em alunos (em grupos) entrevistarem um morador "antigo" da Cidade Alta.

Nesse sentido, a proposta para execução do trabalho consistiu em que os alunos deixassem de lado suas impressões sobre o local e procurassem antigos moradores que tivessem sido removidos, de modo que tentássemos responder a algumas questões trabalhadas em sala: "Como surgiu a Cidade Alta?"; "O que foi o processo de remoção?"; "O que mudou no conjunto ao longo dos quase 40 anos?” (completados no decorrer da pesquisa, em 2009) e, por fim, "O que é uma favela?".

Uma das alterações propostas pelos alunos foi a possibilidade de eles entrevistarem um de seus próprios colegas, membro dos grupos, o que foi feito. Isso aconteceu nas turmas de faixa etária mais avançada. Nas turmas em que 
os alunos eram mais jovens, eles buscaram um parente ou um vizinho próximo.

Dessa primeira leva de trabalhos, de aproximadamente 20 grupos, conseguimos levantar um primeiro panorama do que os moradores antigos, posteriormente tratados por nós como originais, pensavam sobre o conjunto, sobre a vida na favela anterior, sobre o que achou do conjunto quando se mudou para lá, e o que mudou na Cidade Alta ao longo dos anos. As memórias do tempo da favela, dos primeiros anos do conjunto e da favelização posterior foram os discursos que mais se destacaram.

Repetimos essa atividade nos anos de 2007 e 2008, com algumas diferenças relevantes. A primeira delas diz respeito aos conteúdos didáticos explorados com base no trabalho. Notadamente, ao começarmos a lecionar no $3^{\circ}$ ano do ensino médio pudemos relacionar diretamente a atividade com o tema Ditadura Militar (1964-1985) e com o programa de remoções de favelas executado pelos governos federal e estadual, algo que interferiu diretamente nos destinos deles numa questão básica: a moradia.

A maior parte dos removidos veio de favelas localizadas no Leblon e na Gávea, bairros da Zona Sul do Rio de Janeiro, dotados de uma série de vantagens em relação à Cidade Alta quanto a serviços urbanos, segurança, áreas de lazer e urbanização e, por fim, situados junto ou próximo à praia. Dessa forma, introduzimos o assunto nas aulas tratando da questão da imposição do local de moradia e das políticas arbitrárias mediante a remoção de setores mais pobres de uma valorizada Zona Sul, e essa foi a segunda modificação. Embora sem o mesmo conteúdo, nas turmas de $1^{\circ}$ e $2^{\circ}$ ano optamos por manter a mesma proposta de atividade.

Outra modificação foi que o grupo deveria procurar moradores que poderiam ser antigos ou mais recentes, estabelecendo um mínimo de 10 anos de permanência no conjunto (para que o/a entrevistado/a tivesse alguma visão de processo sobre a Cidade Alta), mas não que fossem necessariamente removidos. A única ressalva foi de que o depoente apresentasse alguma característica especial em relação ao conjunto, como ser membro da associação de moradores ou de uma das escolas de samba do local, morador antigo de uma das $f a$ velas ou fundador de uma das igrejas, por exemplo.

Nossa mediação na atividade, além de sistematizar as análises que guiavam a pesquisa no doutorado, era incorporar dados provenientes de outras 
fontes, como documentos oficiais ou notícias em jornais de grande circulação. Buscávamos assim reconstruir a trajetória da Cidade Alta, muitas vezes confrontando os relatos dos alunos, como na narrativa de que o local não seria para favelados e que isso só ocorreu por causa do incêndio da Praia do Pinto. Mostramos que a remoção para a Cidade Alta já se havia iniciado quase 2 meses antes do incêndio.

Por um lado, foi gratificante ver os alunos conhecerem mais sobre a história do local onde viviam, ainda que isso se desse por intermédio de memórias. Por outro, o esforço de pesquisa dos estudantes acabou por fazer surgirem fotos, documentos do Estado (produzidos pelos órgãos de remoção) e jornais que serviram posteriormente de subsídio à nossa pesquisa de doutorado (como ocorreu também na atividade nos anos seguintes).

Assim, ao trabalharmos com essas fontes primárias, no dizer de Bittencourt considerando-as "um instrumento pedagógico eficiente e insubstituível, por possibilitar o contato com o 'real', com situações concretas de um passado abstrato" (Bittencourt, 2004, p.327), pudemos fazer a Ditadura Militar figurar como algo que os alunos pudessem compreender, algo diretamente relacionado às suas vidas, ou às de seus pais e avós.

ESTIGMA, IDENTIDADES E SILÊNCIO:

MEMÓRIAS PERDIDAS DA REMOÇÃO

Com base nos trabalhos e nas múltiplas respostas sobre "o que era" e "o que compunha" a Cidade Alta, percebemos dois elementos:

- A inexistência de uma identidade coesa da Cidade Alta que fosse partilhada por todos ou, ao menos, pela maioria de seus moradores.

- A ausência dessa identidade se ligava à estigmatização de partes e moradores da Cidade Alta, em que "ser" Cidade Alta poderia ser sobretudo uma categoria acusatória, e não uma identidade a ser valorizada e, consequentemente, compartilhada.

Essas questões, apresentadas pelos trabalhos dos alunos, foram guiando a pesquisa e nos levando a algumas considerações e conclusões.

Para Michael Pollack, a memória coletiva de um grupo dá sentido à própria ideia de comunidade, pela formação de uma identidade, sem o uso de 
coerção ou violência, mas pela coesão em noções mínimas de uma identidade que seja partilhada por todos daquele grupo, mantendo a "fronteira" do que o grupo possui em comum, que o diferencia do "exterior" (Pollack, 1992, p.204).

No caso da Cidade Alta, e de todos os elementos que possam ou não compô-la, essa identidade lida com uma violência primeira, simbólica, que foi a pedra angular da imagem do local: o estigma de favelado, fronteira definida pelo "exterior" e introjetada pelos moradores.

De acordo com Pierre Nora, quanto "menos a memória é vivida do interior, mais ela tem a necessidade de suportes exteriores e referências tangíveis de uma existência que só vive através delas” (Nora, 1993, p.14). E segundo Michael Pollack existem "conjunturas favoráveis ou desfavoráveis às memórias marginalizadas” (Pollack, 1989, p.6), ou seja, a memória é construída de acordo com os contextos históricos, posteriores, com que ela depara na busca por se afirmar no presente.

Por parte do Estado, em quaisquer dos seus níveis, não há interesse em construir suportes ou referências exteriores que constituíssem uma "memória da remoção". Uma memória dos tempos em que o Estado foi executor de uma política estigmatizante e segregacionista de imensa parcela da população da cidade.

Pelo lado dos moradores, essa memória também não encontra muitos defensores, reflexo da presença constante do estigma ao longo da trajetória do conjunto e do complexo. O silêncio existente entre gerações sobre a história e a memória locais é revelado pelo desconhecimento, total ou parcial, das gerações mais novas em relação à origem do conjunto e ao "passado" de favela de muitos moradores, dentre os quais, comumente, seus pais e avós. O vivido pelos moradores que foram removidos é pouco ou nada transmitido às gerações mais novas, a não ser em vagas e raras referências.

$\mathrm{Na}$ Cidade Alta, há uma tendência em refutar o passado individual na favela. Busca-se, assim, afastá-lo no presente, de modo que o silêncio em relação ao passado é uma tentativa de impedir que os jovens partilhem de uma origem comum com os considerados favelados. Os jovens não pertencem, portanto, àquele lugar como "os outros pertencem", aqueles moradores dos quais devem manter distância.

Se entre os mais velhos, cuja amostragem por nós analisada eram os alunos do Ensino Médio Noturno, estavam presentes as memórias da favela, da remoção 
e dos primeiros tempos da vida no conjunto, detectamos logo no início da pesquisa (2006-2008) uma amnésia social entre os mais jovens. Tratávamos ainda de alunos do ensino médio, no caso adolescentes acima de 16 anos, de turmas do $3^{\circ}$ ano. Na maioria das vezes, eles tinham por volta de 20 anos.

Essa percepção se intensificou quando iniciamos uma segunda etapa da pesquisa e uma nova fase de trabalhos, em 2009, com os alunos do segundo segmento do Ensino Fundamental na Escola Municipal Ministro Lafayette de Andrada, jovens situados na faixa etária de 11 a 16 anos. A atividade se deu em moldes diferentes dos trabalhos desenvolvidos no colégio estadual, onde a investigação se pautou mais pelo que os alunos mais novos sabiam da história local, ou, em outras palavras, pelo que partilhavam das memórias de seus pais e avós.

$\mathrm{Na}$ escola municipal foi possível tecer várias observações: as memórias da favela anterior; a ligação da Cidade Alta com os outros conjuntos surgidos do programa da CHISAM (Coordenação de Habitação de Interesse Social da Área Metropolitana do Rio de Janeiro, autarquia criada pelo governo federal em 1968 e que existiu até 1973); o processo de remoção e as dificuldades dos primeiros anos da vida no conjunto são, em grande parte, desconhecidos destas gerações mais novas. A maioria tem um vago conhecimento, ou mesmo um pleno desconhecimento da história local.

O trabalho, feito em sala de aula, consistia em o aluno fazer uma redação baseada no que ele conhecesse da história da Cidade Alta, do complexo (ou do conjunto, caso dos que moram no conjunto principal) ou de sua subárea, em sua origem ("como surgiu?"; "por quê?") e nos primeiros anos. Ficou a critério do aluno o que ele deveria escrever nesse trabalho, mesmo quando fosse o caso de ter vagas noções sobre a história ou mesmo de desconhecê-la. Enfim, esse ponto consistia em averiguar a memória de cada aluno sobre a história local. Ele deveria dizer onde morava, destacar os pontos positivos e negativos do local (da subárea e/ou do complexo), se a considerava uma favela, e o que ele mudaria na Cidade Alta.

Separamos os trabalhos prontos em dois grupos, na medida do que as respostas nos possibilitaram: alguns tinham família morando na Cidade Alta há pelo menos três gerações (indicando a vinda no início da sua história); a família dos demais havia se mudado há menos tempo, tendo os pais vindo já adultos para a Cidade Alta, geralmente num prazo não superior a 15 anos de 
moradia. Quando não foi possível alocar o aluno num desses dois grupos, o trabalho foi descartado para nossa pesquisa.

Na maior parte dos trabalhos em que o aluno pertence a uma família moradora "recente" do conjunto, o desconhecimento da origem deste é quase total, exemplificado nos trabalhos que citaremos. Um aluno, cuja família foi para lá por vontade própria, há 15 anos aproximadamente, escreveu: "Não sei como surgiu a Cidade Alta, e ainda não ouvi comentários sobre isso". ${ }^{3}$ Outro aluno narrou que sua família veio de Jacarepaguá, região onde não houve remoções de favelas pela CHISAM, e disse: "Eu, sinceramente, não sei como minha avó, meus tios e minha mãe, quando não era casada, veio parar aqui. Todos eles moravam em Jacarepaguá" ${ }^{4}$ Emblemática é a redação de uma aluna cuja família veio de São João de Meriti, na região metropolitana do Rio: "Eu moro na Cidade Alta desde 1995, e nunca tive curiosidade de saber como surgiu". ${ }^{5}$

Somado ao relativo pouco tempo de moradia, podemos ver que a inclusão no conjunto por opção própria, pelos motivos que discutimos anteriormente, também é um fator preponderante para o desconhecimento da origem deste. Assim, uma jovem moradora do Porto Velho, cuja avó, não removida, foi uma das primeiras moradoras do conjunto (segundo a família), também disse não conhecer a origem: "Não sei como surgiu e nem por que minha família veio morar aqui". ${ }^{6}$

Nos casos, porém, de alunos cujas famílias vieram por remoção, vimos que, quase sempre, o jovem partilha de uma memória fragmentada do passado de favela da sua família, sem clareza quanto à vinculação da remoção com o surgimento do conjunto, como aparece neste relato: "Eu não sei como surgiu. Minha família mora aqui há mais de 30 anos. Antes de morar na Cidade Alta, minha família morava no Parque da Gávea" ${ }^{7}$

Mas ainda que o aluno não tenha clareza quanto ao processo de remoção, suas falas evidenciam um antes e um depois, em que Praia do Pinto e Cidade Alta podem se confundir geograficamente, como podemos ver nos casos a seguir. O primeiro é de um aluno cuja avó veio por remoção, dizendo que a elevação onde se encontra atualmente, a Cidade Alta, "não tinha nada. Só tinha mato, ladeiras, o chão era de pedras e areia. Uma tremenda favela. Com o tempo, pessoas vieram morar aqui e homens de família começaram a construir casas, prédios etc. Lembrando que a Cidade Alta não era conhecida como Cidade Alta, e sim como Morro do Pinto". ${ }^{8}$ Percebe-se que o aluno tem a 
memória da ruptura da Praia do Pinto, em que esta figura como favela (inclusive chamada erroneamente por ele de "morro", evidenciando esse entendimento), e da "regeneração" do local a partir do surgimento e da mudança da nomenclatura para "Cidade Alta".

Outra aluna tem a mesma linha de raciocínio: "A Cidade Alta surgiu como Morro do Pinto. Ela era cheia de mato, não tinha prédios, os Bancários, nem o Pé-Sujo, nada. Só tinha os barracos. Com o tempo, muitos dos barracos foram se destruindo e surgindo os prédios, e as ruas foram ficando com asfalto e foram aparecendo os comércios". ${ }^{9}$

Entretanto, alguns jovens compartilham a memória da saída de suas famílias da favela anterior como algo imposto, ainda que não tenham clareza sobre a maneira como isso estava ligado à construção do conjunto: "Eu não sei como surgiu a Cidade Alta, mas eu já escutei dizer que pessoas foram expulsas de uma outra favela e vieram para cá". ${ }^{10}$

Outra aluna teve a família do pai transferida por escolha própria para a Divineia, no início dessa comunidade, viveu no conjunto da Cidade Alta e atualmente mora na Avilã. Ela tem uma visão mais profunda de toda a trajetória do complexo, vivida diretamente pela família dela: "Pelo que eu sei, moradores de outro lugar vieram para a Cidade Alta há muito tempo, e aqui construíram prédios e casas, mas quem não podia pagar, construía pequenos barracos para si". ${ }^{11}$

Em outra redação, ainda que a aluna tenha uma memória mais clara desse processo, o termo "remoção", ou qualquer similar, não é utilizado por ela para explicar o porquê de sua família ter saído da Praia do Pinto para a Cidade Alta ou, ainda, de outras terem ido para a Cidade de Deus: "Houve um acontecimento na Praia do Pinto e começou o fogo a se espalhar pelos barracos, as pessoas só conseguiram pegar as coisas que davam. Aí, no outro dia, um senhor apareceu lá, todos na rua deitados no chão, e falou assim: 'Tem moradia numa favela que é a Cidade Alta e na Cidade de Deus'. Quem ia para a Cidade de Deus, queria casas, e para cá, queria apartamento". ${ }^{12}$ A referência, inclusive à Cidade Alta como favela, evidencia o desconhecimento em relação ao projeto governamental de remoção de favelas, no qual a Praia do Pinto de seus avós estava incluída.

As imagens do incêndio aparecem com força em várias redações, até mesmo figurando como a motivação maior para a transferência para a Cidade Alta. 
Uma aluna escreveu: "Como surgiu a Cidade Alta eu não sei, mas sei que minha família veio para cá porque puseram fogo na Praia do Pinto". ${ }^{13}$

Na redação de um jovem, o seu discurso sobre o "passado" do local - segundo ele, contado pelo avô -, o estigma de favela na Cidade Alta é traçado, de maneira clara, como uma trajetória em espiral, em que passado e presente de favela se mesclam na narrativa do jovem sobre a história da comunidade: "A Cidade Alta, pelo que meu avô me disse, ela era uma cidade cheia de barro, sem asfalto e bem depois, depois de anos, eles vieram e colocaram paralelepípedo. E depois de anos também vieram colocar nosso asfalto. Mas o meu avô veio para cá porque a Praia do Pinto pegou fogo, e não tinha como eles ficarem lá. Então, eles foram colocando as pessoas em cada favela ou comunidade". ${ }^{14}$

\section{NOVAS GERAÇÕES, O ESTIGMA COMO MEIO}

Os alunos desses relatos foram por nós classificados como pertencendo à terceira geração de moradores da Cidade Alta, filhos dos que vieram ainda crianças ou netos dos que vieram já adultos. E seus relatos são pista preciosa para a compreensão acerca da reprodução do estigma de favela.

No processo de pesquisa e desenvolvimento do trabalho em sala de aula vimos que as acusações do que é "ser favelado" surgem de determinadas características atribuídas a um tipo de comportamento, mais que de uma condição econômica per se, embora esta seja um determinante que não se pode desconsiderar, ao menos como originador de práticas e/ou justificador de condutas (como nos casos da formação dos primeiros barracos e dos primeiros "gatos" de luz).

As autoridades por trás do programa remocionista o fizeram baseando-se no pressuposto de que o meio da favela determinava uma série de comportamentos e atitudes que conformavam o "favelado". Mas não podemos desconsiderar uma especificidade, destacada constantemente pelas fontes aqui utilizadas, orais ou documentais, de que "algo" há num local que - mais que as formas das habitações, o nível socioeconômico, a presença de quadrilhas, a existência ou não de uma infraestrutura de serviços (da qualidade que for), as práticas entre informais e ilegais - constitui uma imagem externa que se reflete numa autoimagem que, afinal, os leva a denominá-lo "favela". 
Assim, seria enganoso concluir que não há diferenças relevantes que justifiquem a existência do termo "favela" como uma representação social de moradores e moradias, intrinsecamente ligados, como a construção simbólica de um lugar onde existe o que não deveria existir na cidade. Afirmar essa especificidade não significa corroborá-la e, menos ainda, justificá-la, postura que, a nosso ver, é mais provavelmente tomada quando se ignoram as diferenças existentes entre a favela e a "cidade formal". Que movimentos sociais, notadamente os de favelas, o façam, é justo, e de fato eles contribuem para que essas diferenças sejam eliminadas. Mas essa não pode ser a tarefa do professor, historiador ou cientista social.

Estaríamos, assim, ao fim e ao cabo, endossando os argumentos da remoção da favela como meio pernicioso, e de que combatê-la é preciso, por ser ela o meio em que determinadas práticas subsistem e se estruturam? Nosso ponto de inflexão em relação a esse argumento é que não é a favela o meio, e sim o estigma. Ao descrever a favela, o estigma constitui a alteridade desta em relação ao que seria "normal". A favela, ao ser descrita como lugar onde as regras não são cumpridas, leva muitos moradores a se sentirem cada vez mais desobrigados de cumpri-las. O meio, a área estigmatizada, condiciona as práticas como uma espécie de profecia que se autocumpre.

As gerações mais novas cresceram numa Cidade Alta em que o estigma de favela atuava fortemente sobre a identidade local. A violência urbana derivada do tráfico, fortemente associada à condição de favela, foi mais um elemento com que as novas gerações tiveram de lidar.

\section{"FAVEla” OU “COMUnidAdE”, A Disputa dos TERmos}

Outro aspecto que, mais do que demonstrar diferentes leituras da Cidade Alta com base em cortes geracionais, revela o quanto a caracterização do local como favela foi sendo consolidada, é o uso ou não do termo "comunidade" por parte do morador para se referir ao local.

O termo comunidade é geralmente usado como forma que "abrandaria" a carga negativa que a palavra favela possui, por moradores das favelas cariocas ou pelos que pretendem adotar um tratamento que seria mais respeitoso em relação a elas. De acordo com Márcia Leite, "na atualidade, o recurso à ideia de 'comunidade' nas narrativas de seus moradores seria uma forma de 
reconstruir esse espaço, conferindo um sentido positivo para o território e seus moradores" (Leite, 2008, p.125).

As gerações mais recentes de famílias que moram na Cidade Alta há mais de 25 anos, pelo menos, não têm parâmetros de comparação com a "não favela", seja em outro local, seja na Cidade Alta. Assim, esses jovens, como os daquelas famílias que se mudaram para a Cidade Alta mais recentemente, tendem, em sua maioria, a não hesitar em assumir o termo "comunidade" quando se referem ao local onde moram, de maneira a reduzir o peso do termo favela.

É o que vemos no relato de uma jovem, moradora de terceira geração, em sua redação: "Eu não acho que a Cidade Alta é uma favela. Eu acho que ela é uma comunidade. É claro que existem favelas aqui, mas eu acho que nem só por isso seja uma favela. Continuo achando ela uma comunidade". ${ }^{15}$

Outro jovem, cuja família se mudou há menos de 20 anos para o conjunto da Cidade Alta (ele, com 14 anos, nasceu lá), tem uma opinião sobre a Cidade Alta fortemente influenciada pela visão da favela como ambiente de ausência e precariedade: "A Cidade Alta não é uma favela. Se fosse favela não ia ter ônibus nem escola. Para mim, aqui é uma comunidade". ${ }^{16}$

Os termos comunidade e favela também podem ser usados indistintamente na fala dos jovens. Vemos isso na redação de uma aluna ao responder se considerava o local uma favela: "A Cidade Alta é favela sim. Não tem organização na comunidade, é uma bagunça"; mais à frente, apontou o que considerava bom no local: "é que tem bastante atividade para fazer nessa comunidade". ${ }^{17}$

Outra jovem faz uma análise emblemática acerca da condição de favela do complexo e das relações entre as partes que o compõem: "A comunidade da Cidade Alta surgiu há muito tempo atrás ... moro numa parte melhor da Cidade Alta, moro no Bancários. É um condomínio, então não é tão bagunçado ... Não acho a Cidade Alta um lugar muito ruim, porque sei de favelas piores". ${ }^{18}$

Para o caso dos moradores mais velhos, a clivagem bem definida entre conjunto habitacional e favela inutiliza esse tipo de abrandamento, pois, ao preferir o termo comunidade, o morador imediatamente estaria estabelecendo a sua condição de "não conjunto" e, ao fazê-lo, indicaria de modo categórico ser a Cidade Alta uma favela. Analisando os depoimentos à pesquisa, vimos que o termo é pouquíssimo empregado entre moradores mais velhos da Cidade Alta. 


\section{JOVENS, ESTIGMAS E IDENTIDADES}

Como apontado por todos os depoentes, hoje o tráfico de drogas é um elemento que indica uma degradação da Cidade Alta e a ideia de favelização do complexo como um todo. Assim, pais e mães da Cidade Alta temem que seus filhos cedam ao apelo do dinheiro relativamente fácil e da sensação de poder que a atividade do tráfico traz. E isso gera uma tentativa, por parte de alguns moradores, de se diferenciarem de outros, negando os laços construídos com o próprio lugar.

Afastar-se da ligação com o local é uma tentativa de rejeição não só à degradação espacial do conjunto/complexo (sempre feita pelos outros), mas também às manifestações "culturais", códigos e formas de sociabilidade que seriam próprios de quem "mora na favela". Por exemplo, no relacionamento com o tráfico, os mais jovens costumam ser suscetíveis a "ter contexto", ou seja, manter uma relação de proximidade maior que a desejada por seus pais e avós.

Assim, o surgimento da Cidade Alta a partir da remoção de favelas é um elemento estruturante da(s) identidade(s) local(is). Seja pela ocultação desse passado, percebida na ausência dessas memórias nas gerações mais novas, consequência direta do processo de remoção da favela de si, com o silêncio em relação ao passado, seja pelos processos internos de diferenciação, com a acusação e manipulação do estigma entre os vizinhos na Cidade Alta, sejam eles vizinhos de porta, de conjuntos, de favelas, de bairro etc.

É possível perceber que para os moradores da segunda geração em diante não há uma memória individual do passado de favela ou, mais especificamente, na favela. Assim, para os moradores que viveram a remoção tendo passado já da primeira infância, houve possibilidade de as suas memórias da favela conjugarem tanto os aspectos considerados negativos quanto os considerados positivos. Por exemplo: de um lado, a possível precariedade da habitação e saneamento; de outro, porém, a facilidade de mercado de trabalho, serviços e lazer e as relações de vizinhança.

Já para os seus filhos nascidos na Cidade Alta ou removidos muito novos, essa memória só pode se realizar de maneira coletiva, por meio de falas, de fotos, enfim, de referências que a primeira geração tenha transmitido, claro que num processo que nem é consciente nem pode ser totalmente "controlado". 
Ocorre então que, para muitos a partir da segunda geração, esse passado de favela, sendo coletivo, tende a destacar os aspectos considerados negativos da favela, e refutados.

Outra categoria existente no local são os "não removidos", que tanto podem ser moradores inseridos - que foram para a Cidade Alta no processo de inauguração do conjunto e queriam morar num apartamento próprio, sendo a ida algo espontâneo, cujos custos e benefícios haviam sido calculados - ou os que se mudaram para o conjunto ao longo da trajetória de 40 anos. Para "não removidos", o passado de favela não é, portanto, fundamental na sua identidade, a não ser para refutá-lo ao apresentar-se como não removido. Assim, a memória local é preenchida também com discursos que não transmitem a memória de favela, mas ao contrário, a negam.

Desse modo, chama atenção que exista uma memória, partilhada por alguns moradores, de que a Cidade Alta originariamente não se destinava a removidos. Percebemos, nesses discursos, a intenção de negar que o estigma de favela aplica-se a si próprio, no que a argumentação se baseia em dois principais pontos, não necessariamente articulados entre si. Num deles, tenta-se apagar o estigma de favela da "origem" do conjunto e, assim, do seu passado individual - a favela teria sido deixada para trás, a ida para lá teria sido um recomeço, e o estigma de ser favelado estaria, assim, eliminado, ou, para os não removidos, sequer poderia ser aplicado. O outro ponto focal da argumentação seria de que a Cidade Alta, jamais tendo sido destinada a favelados, foi favelizada justamente porque aqueles não superaram essa condição, de modo que, ao imputar ao outro a acusação de ser favelado, afasta-se ainda mais o estigma de si.

\section{CONSIDERAÇÕES FINAIS}

Em 2010 encerramos essa atividade com os alunos das duas escolas, tendo feito algumas atividades posteriores de retorno dos resultados da pesquisa e da sua publicação em livro, quase sempre atividades comemorativas da fundação da Cidade Alta. Além disso, parte do acervo reunido pela pesquisa ficou aos cuidados da Biblioteca Comunitária da Cidade Alta, que funciona na paróquia local.

De um lado, nossa intenção desde o início, em relação à atividade docente, era aproximar dos alunos um tema algo "abstrato" na realidade deles, a 
Ditadura. No caso dos moradores de conjuntos habitacionais surgidos por remoções de favelas em 1969 e 1971, a Ditadura significava menos as restrições à organização partidária, sindical ou estudantil; menos ainda a questão da repressão policial, tortura e desaparecimento de presos, realidade pouco modificada nos espaços periféricos e/ou de baixa renda de nossas metrópoles.

No processo ensino-aprendizagem relacionado à pesquisa, o arbítrio surgia da expulsão deles, ou de seus pais e avós, do local onde moravam, significado por eles como um local "melhor" e "dos ricos", para "longe", para um lugar "pior".

Nessas oportunidades, tratamos mais de caracterizar o que foi a Ditadura Militar e de explicar por que foi possível a remoção forçada de pessoas, a não possibilidade de resistência, qual a relação do Estado com a parte mais pobre de sua população etc. Enfim, buscamos fazer o aluno compreender que sua história pessoal se integrava a um conjunto maior de processos e "histórias", identificando-a como "parte do todo" e se situando dentro desse "todo" (Morin, 2007, p.25).

Essas aulas possibilitaram discussões interessantes quando, por exemplo, uma aluna questionou se no quadro atual (fins da década de 2000) seria possível uma remoção em massa das favelas do Rio sem a reação de traficantes.

E esta foi a segunda questão tratada na pesquisa: compreender a narrativa que os alunos faziam do local onde nasceram e/ou moravam. Uma narrativa que para os mais velhos valorizava o local no passado, acompanhada quase sempre do discurso de um processo de depreciação por vários elementos, e que nos mais jovens era repleta de lacunas sobre a origem.

Tanto na pesquisa propriamente acadêmica, a que se tornou tese, quanto no processo de envolvimento dos alunos, o processo vivo, conseguimos torná-los articuladores da própria história. Não só como sujeitos históricos, mas também como historiadores que conseguiram produzir um saber que deu sentido à realidade que os cercava e cujas consequências viviam cotidianamente. Eles foram artífices da criação, de modo coletivo, de uma nova visão do local, agora acrescida dos processos que deram origem ao conjunto e do conhecimento de quem eram os moradores originais, além do debate sobre o que aconteceu ao longo dos anos.

Nesse sentido, pudemos também tratar, com algumas restrições impostas pela realidade, do crescimento do tráfico de drogas e da violência urbana no 
Rio de Janeiro nas décadas de 1980 e 1990, a partir da escala local, mas relacionando com o contexto da cidade e do país; das consequências sociais da Ditadura Militar e dos dilemas da cidadania na Redemocratização do Brasil.

Destaca-se que o tráfico foi um elemento constante na pesquisa e em vários trabalhos e depoimentos. As narrativas sempre contrastavam um passado de paz e tranquilidade ao presente de violência. Nesse sentido, a atividade como um todo gerou debates sobre a historicidade da violência local e questões entre os alunos sobre as suas causas e a possibilidade de ruptura com esse cotidiano, muitas vezes desalentador, principalmente para os que conheceram “outras épocas".

Foi possível reconstruir o processo histórico das favelas cariocas e das relações entre elas e a cidade, verificar a construção dos estigmas e como eles eram aplicados a locais como a Praia do Pinto, ao Parque Proletário da Gávea e à Cidade Alta, numa espiral permanente de acusações sociais e de opções políticas nas quais os alunos passaram a se perceber como agentes desse processo.

Assim, mais do que reificar ou desfazer estigmas, no caso, o de favela, o retorno dos trabalhos por meio de debate após a entrega serviu para os alunos perceberem que havia uma rica dinâmica interna na Cidade Alta, e que as visões sobre o que é o local, e mais, sobre o que significa favela, têm diferentes respostas e mesmo têm mais de uma resposta possível.

Segundo Bittencourt e Nadai, o papel do docente é situar o aluno diante das permanências e rupturas da sociedade e de sua ação como agente histórico (Bittencourt; Nadai, 1991). No que a conjugação entre ensino e pesquisa cumpre papel fundamental, como pudemos observar. O objetivo de fazê-los perceberem-se como agentes e pessoas dotadas de história foi plenamente alcançado, já que não se tratou de uma transmissão de saberes da parte do docente, e sim de uma produção em que o docente atuou como mediador.

Concluindo este artigo, atingimos nossos objetivos propostos com a pesquisa na realização de diversos encontros:

O primeiro foi o encontro entre a pesquisa e a atividade docente. Só foi possível realizá-las com forte amparo mútuo, de modo que a pesquisa obteve nas aulas a maior parte de suas fontes, ao mesmo tempo em que subsidiava uma atividade na qual os alunos e o professor aprendiam, mais do que a história local, o procedimento histórico. 
Encontro entre História Local e a História do Brasil, em que as diferentes escalas foram trabalhadas e compreendidas pelos alunos, eles mesmos se identificando como sujeitos históricos.

Encontro também entre gerações que partilhavam uma origem comum e a vivência cotidiana no local, mas que possuíam visões e discursos diferentes sobre ele e sobre o processo. As diferentes representações que alunos/moradores faziam da Cidade Alta foram objeto de reflexão, não para encontrarmos a(s) certa(s), mas para compreendermos o quadro em que elas foram geradas.

Por último, encontro entre o vivido, o que os alunos sabiam e representavam sobre a Cidade Alta, e o saber científico a ser trabalhado pedagogicamente em sala de aula, enriquecido por eles mesmos. Mais do que opostos, esses saberes se complementavam e puderam ser incorporados à História, como disciplina escolar, como ciência e, por fim, como a trajetória deles no tempo, seja na escala global, seja na local - fosse ela sua casa ou a sala de aula.

\section{REFERÊNCIAS}

BITTENCOURT, Circe. Ensino de História: fundamentos e métodos. São Paulo: Cortez, 2004.

BITTENCOURT, Circe Maria; NADAI, Elza. Repensando a noção de tempo histórico no ensino. In: PINSKY, Jaime (Org.) A criação do fato histórico. São Paulo: Contexto, 1991. p.74-91.

BRUM, Mario Sérgio Inácio. Cidade Alta. Rio de Janeiro: Ponteio, 2012.

LEITE, Márcia Pereira. Violência risco e sociabilidade nas margens da cidade: percepções e formas de ação de moradores de favelas cariocas. In: MACHADO DA SILVA, Luiz Antonio (Org.) Vida sob cerco: violência e rotinas nas favelas do Rio de Janeiro. Rio de Janeiro: Nova Fronteira, 2008. p.115-141.

MONTEIRO, Ana Maria. A história ensinada: algumas configurações do saber escolar. História \& Ensino, Londrina, v.9, out. 2003.

. Ensino de História: entre História e Memória. In: SILVA, Gilvan Ventura da; SIMÕES, Regina Helena Silva; FRANCO, Sebastião Pimentel (Org.) História e Educação: territórios em convergência, Vitória, v.1, 2 sem. 2007.

. Entre o estranho e o familiar: o uso de analogias no ensino de história. Cadernos Cedes, Campinas, v.25, n.67, p.333-347, set./dez. 2005.

MORIN, Edgar. Educação e Complexidade: os sete saberes e outros ensaios. São Paulo: Cortez, 2007. 
NORA, Pierre. Entre memória e história: a problemática dos lugares. Projeto História, São Paulo, v.1, n.10, p.7-28, 2º sem. 1993.

POLLACK, Michael. Memória e Identidade Social. Estudos Históricos, v.5, n.10, p.200-212, 1992.

. Memória, esquecimento, silêncio. Estudos Históricos, v.2, n.3, p.3-15, 1989.

SCHMIDT, Maria Auxiliadora; CAINELLI, Marlene. Ensinar História. São Paulo: Scipione, 2004.

\section{NOTAS}

${ }^{1}$ Este artigo deriva da pesquisa de doutorado Cidade Alta: História, memórias e estigma de favela num conjunto habitacional do Rio de Janeiro, desenvolvida no PPGH-UFF sob orientação do prof. dr. Paulo Knauss e defendida em junho de 2011, que recebeu menção honrosa da Anpuh-RJ e foi publicada na forma do livro BRUM, 2012.

${ }^{2}$ Classificaremos aqui os moradores como de primeira geração, aqueles que chegaram adultos nos primeiros anos do conjunto; de segunda geração, moradores que chegaram muito novos ou mesmo que nasceram na Cidade Alta em seus primeiros anos; e os de terceira geração, que tenham nascido na Cidade Alta e sejam filhos da segunda geração. Vale lembrar que muitos moradores vieram ao longo dos 40 anos de existência da Cidade Alta, e que por não serem fundadores nem possuírem raízes anteriores não serão enquadrados nessa classificação.

${ }^{3}$ Durante toda a pesquisa, para identificar os trabalhos, usamos a seguinte codificação: por escola, os trabalhos poderiam ser dos alunos do Colégio Guiné Bissau (GB) ou da Escola Lafayette (LA) para identificar a escola; seguido do ano letivo em que foi produzido (de 2006 a 2010, último ano em que foi feito com os alunos); pela turma em que foi feito e, por último, um código de identificação do aluno ou grupo que o fez. Assim, chegamos à codificação seguinte, já usada na prática aqui: Trabalho LA2010/1901-01.

${ }^{4}$ Trabalho LA2010/1901-05.

${ }^{5}$ Trabalho LA2010/1901-06.

${ }^{6}$ Trabalho LA2010/1902-13.

${ }^{7}$ Trabalho LA2010/1901-03

${ }^{8}$ Trabalho LA2010/1902-01

${ }^{9}$ Trabalho LA2010/1902-02

${ }^{10}$ Trabalho LA2010/1902-16

${ }^{11}$ Trabalho LA2010/1902-14.

${ }^{12}$ Trabalho LA2010/1902-09. 
${ }^{13}$ Trabalho LA2010/1902-03.

${ }^{14}$ Trabalho LA2010/1902-12.

${ }^{15}$ Trabalho LA2010/1902-04

${ }^{16}$ Trabalho LA2010/1901-10

17 Trabalho LA2010/1902-18

${ }^{18}$ Trabalho LA2010/1901-04

Artigo recebido em 21 de novembro de 2014. Aprovado em 23 de fevereiro de 2015. 